\title{
Factors influencing the work passion of Chinese community health service workers: an investigation in five provinces
}

\author{
Zhenni Luo ${ }^{1,2}$, Xue Bai ${ }^{1}$, Rui Min ${ }^{1}$, Changmin Tang $^{3}$ and Pengqian Fang ${ }^{1 *}$
}

\begin{abstract}
Background: After the implementation of new healthcare reform, Chinese government paid increasing attention to developing community health service (CHS). The current focus is mainly on cultivating community general practitioners but paying less attention to the working status and occupational demands of in-service CHS workers. Work passion is playing an important role for medical workers. With work passion, CHS workers' team will become more stable and more effective, ensuring the sustainable development of CHS system. At present, the work passion of CHS workers is relatively low. Studying on influencing factors of work passion of CHS workers, promoting their work passion, and making them keep enthusiasm for work are significant.

Methods: A total of 100 CHS organizations were sampled randomly in 10 cities from 5 Chinese provinces for this study. A total of 3450 CHS workers from these CHS institutions took part in the surveys. Questionnaires were used to collect data, including socio-demographic information, work passion and opinion on influencing causes, and work-related satisfaction. Pearson chi-square statistical method was used to identify the factors related to CHS workers' work passion. Binary logistic regression was performed to determine the significant factors that influence CHS workers' work passion.

Results: A total of $38.77 \%$ of those who accomplished the questionnaire expressed that they didn't have passion for current work. The related factors that influence CHS workers' work passion are (1) socio-demographic factors such as age, and years of employment, and (2) other work-related factors such as learning and training opportunities, compensation packages, work stress, and personal development opportunities. CHS workers were most dissatisfied with the balance between remuneration and workload, job promotion opportunities.

Conclusions: Based on the results, the government should concern for CHS workers' working status and work-related demands, pay more attention and meet their demands for reasonable compensation packages and self-development, balance the income and workload, provide more learning and training opportunities and personal development opportunities for CHS workers, in order to promote CHS workers' work satisfaction, improve their work passion and enthusiasm.
\end{abstract}

Keywords: Community health services, Community health workers, Work passion, Health care reform, China

\footnotetext{
* Correspondence: pfang@mails.tjmu.edu.cn

'School of Health and Medicine Management, Tongji Medical College, Huazhong University of Science and Technology, 13 Hangkong Road, Wuhan, Qiaokou District 430030, China

Full list of author information is available at the end of the article
} 


\section{Background}

Healthcare system has three levels in urban area in China. The top level includes large-scale tertiary hospitals; the middle level includes medium-scale secondary hospitals; and the basic and primary level includes community health services (CHS) institutions providing primary healthcare services. CHS institutions are small-scale medical institutions located in urban communities in China, usually providing out-patient diagnosis and treatment, and in-patient care and treatment of common disease and chornic disease for community resident. For China and many other countries in the world, CHS system is an important part of healthcare system.

Many countries have developed an efficient CHS system, as evidenced by the involvement of stable and professional CHS workers and the provision of good healthcare services to community residents [1]. The $\mathrm{CHS}$, which is mainly concerned with general practice and community care [2], can help to optimize the allocation of health resources and offer convenient and humanistic medical services while helping control the high costs of medical treatment $[3,4]$. Many countries provide satisfactory primary medical services to residents by producing well-trained community general practitioners and community nurses [5-7]. However, in China, the education and development mechanism of community general practitioners and nurses is not good enough [8].

Differences in local conditions create different structures and patterns of CHS system. Many countries have been prioritizing the developing CHS, and China is no exception. In 2006, the state council promulgated "Guidelines on the Development of City CHS [No. 10 (2006) of the State Council] and "Guidelines on Strengthening the Role of Urban Community Health Personnel" [No. 69 (2006) of the Ministry of Human Resources and Social Security]. The goals were to develop an improved urban CHS system for China, strengthen the role of community health human resources, and improve general practice and community care. In 2009, China began to implement another set of medical and health system reform that focused on developing CHS system as the foundation and center of health work in the future, presented applicable measures, and set the goal of cultivating, developing, and stabilizing CHS talent [8].

At present, urban CHS of China has attained much progress and development. As of April 2013, a total of 33,990 CHS institutions have been organized throughout the country [9]. In the first quarter of 2013, CHS institutions have diagnosed a total of 194,470,000 people and achieved a hospital bed utilization rate of $58.8 \%$, with an average length of stay of 9.7 days [10]. However, the development of CHS human resources is limited, as well as the technical capability. The income and training opportunities of $\mathrm{CHS}$ workers are relatively less than those of medical workers in hospitals.

Chinese CHS provides basic diagnostic and treatment services for disease prevention, keeping fit, recuperating health, health education, family planning technical service, common diseases, frequently encountered diseases, and chronic diseases [11]. However, according to the former studies on the residents, only less than $30 \%$ of the residents are willing to choose $\mathrm{CHS}$ as the preferred option for treatment. Many residents who had received services from CHS once are not very satisfied $[12,13]$, because they do not have enough confidence in CHS [14] and think that the technical capability of CHS is insufficient $[15,16]$.

According to the former studies, CHS workers have relatively low work passion, low work efficiency, low work satisfaction, high demission rate, are not well educated, and possess poor professional skills, among others $[17,18]$. However, CHS workers are crucial for the excellent performance of the CHS [19]. Their working situation is directly related to community medical care safety, service quality, worker-patient relationship, patient satisfaction, and management and operational aspects of CHS institutions [20].

For one' s work, passion is "a psychological state with the characteristics of strong and positive encouraging emotion, internal driving force, and putting into meaningful work with whole attention [21]", and is having freshness and initiatives in work, having enthusiasm for work and keeping in a good working condition. Work passion is playing an important role for medical workers. With work passion, CHS workers' team will become more stable and more effective, ensuring the sustainable development of CHS system. While, if CHS workers are lack of work passion, they are more likely to develop several problems such as low work efficiency, more emotional exhaustion, more job burnout, and more turnover intention [22]. All these problems will influence the quality of patients' treatment and care. Thus, probing into the current factors that influence the work passion of CHS workers, promoting their work passion, and making them keep enthusiasm for work are significant.

The purpose of this study is to analyze and determine the main related factors that influence work passion of CHS workers by investigating CHS workers from five Chinese provinces. We aim to avoid work passion loss, arouse work passion, motivation and enthusiasm for work, promote work efficiency, and reduce job burnout and turnover intention, to provide high-quality medical services to community residents and meet the basic health service demands of community residents.

\section{Methods}

This study was approved by the Tongji Medical College Ethics Committee of Huazhong University of Science 
and Technology (IRB No: FWA00007304). The respondents were properly informed, and their voluntary participation was sought. The respondents were assured of the confidentiality of their data and responses.

\section{Study population}

A multi-stage sampling method was used to select the participating $\mathrm{CHS}$ institutions. In order to make the samples more representative, considering that China is a large area, we initially selected five provinces in eastern region, southern region, western region, northern region and central region of China respectively according to geographical locations. Subsequently, two cities were selected from each province. In order to reduce influence of different economy, these ten cities are at the similar economic development level. Finally, a list of all the CHS institutions was offered by health department in each city and $10 \mathrm{CHS}$ institutions were randomly selected from each of the ten cities. Thus, this study comprised $100 \mathrm{CHS}$ institutions.

In each selected CHS institution, all CHS workers were selected as respondents, including doctors, nurses, public health workers, and medical technicians. The total number of respondents was 3450, which comprised 801 from Hubei province, 633 from Guizhou province, 474 from Hebei province, 912 from Guangdong province, and 630 from Zhejiang province. A total of $3450 \mathrm{CHS}$ workers were investigated and 3220 valid answer sheets were returned, resulting in a response rate of $93.33 \%$. In order to ensure and control the quality of the questionnaires, one-on-one, face to face questionnaire survey method is taken.

\section{Questionnaire}

The questionnaire comprised three parts, namely, sociodemographic information, work passion and influencing causes, and degree of work satisfaction. The items of the questionnaire were validated and the value of Cronbach's Alpha is 0.875 for reliability statistics.

The socio-demographic information included gender, age, educational background, position, professional title, and years of employment.

The investigation on work passion and influencing causes included two parts. The first part is one question on whether CHS workers feel themselves having work passion for current work or not. The second part included questions on their opinions about the factors that may influence work passion, such as compensation packages, learning and training opportunities, personal development opportunities, interpersonal relationships and team atmosphere, work stress, workload, working conditions and environment, and opportunity to work autonomously. In each question of this part, two options were provided to express the opinion: 1 , yes; 2 , no.

Adapting the Minnesota Satisfaction Questionnaire and based on the actual situation of CHS workers in China, we developed a 10-item general work satisfaction inventory. The investigation on the degree of work satisfaction of CHS workers included satisfaction on the opportunities to develop capacity for work, decision-making ability of superior, the stability level of job, superior's attitude toward subordinate, self-decision in completing the job, methods and measures for implementing organization policies, sense of achievement from work, working conditions, job promotion opportunities, and balance between remuneration and workload. A five-point Likert scale was used to rate satisfaction degree in these aspects, with "option1" denoting "very dissatisfied" and scoring 1 point; " option 2" denoting "dissatisfied" and scoring 2 points; "option 3" denoting "moderate (not too bad)" and scoring 3 points; "option 4" denoting "satisfied" and scoring 4 points; and "option 5 " denoting "very satisfied" and scoring 5 points. Then, the score of work-related satisfaction degree was calculated.

\section{Statistical analysis}

EpiData 3.1 was used to establish a database, and double machine inputting method was used to enter the collected data into the computer. PASW18.0 (SPSS) was used to perform related statistical data analysis. The sociodemographic factors of the investigated CHS workers were summarized using a descriptive statistical analysis method. Pearson chi-square statistical method was used to assess whether these socio-demographic factors and other factors were related to CHS workers' work passion. Binary logistic regression was then performed to determine the significantly factors that influence work passion loss. The dependent variable included the following criteria: lose work passion (1) or have work passion (0) for current work. We substituted the variables with statistical significance determined from Pearson chi-square statistical test into the binary logistic regression model for calculation $(P<0.05)$. Odds ratio (OR) was reported at a $95 \%$ confidence interval $(\mathrm{CI})$ where appropriate. All of the tests were conducted at $5 \%$ significance level.

\section{Results}

\section{Socio-demographic characteristics of CHS workers}

The largest proportion of age of the investigated CHS workers ranged from 25 and 34 (37.0\%), and about half of the investigated CHS workers were female (51.1\%). The largest proportion of educational degree was junior college (56.2\%), and the largest proportion of professional title was junior level title (67.7\%; Table 1). In this study, different professional titles showed various professional skill levels of the medical workers. In China, a medical worker needs to undergo and pass a special qualification examination and assessment to achieve his (or her) professional title corresponding to a particular professional skill level. 
Table 1 Socio-demographic features of the investigated CHS workers in five Chinese provinces

\begin{tabular}{|c|c|c|}
\hline Characteristic & $\begin{array}{c}\text { CHS workers } \\
(\mathrm{n}=3220)\end{array}$ & Percentage (\%) \\
\hline \multicolumn{3}{|l|}{ Gender } \\
\hline Male & 1574 & 48.9 \\
\hline Female & 1646 & 51.1 \\
\hline \multicolumn{3}{|l|}{ Age } \\
\hline 24 or below & 728 & 22.6 \\
\hline $25-34$ & 1191 & 37.0 \\
\hline $35-44$ & 911 & 28.3 \\
\hline $45-54$ & 338 & 10.5 \\
\hline 55 and above & 52 & 1.6 \\
\hline \multicolumn{3}{|l|}{ Educational background } \\
\hline Secondary technical school and below & 808 & 25.1 \\
\hline Junior college & 1810 & 56.2 \\
\hline Bachelor's degree & 596 & 18.5 \\
\hline Master's degree or above & 6 & 0.2 \\
\hline \multicolumn{3}{|l|}{ Position } \\
\hline Doctor & 1117 & 34.7 \\
\hline Nurse & 1036 & 32.2 \\
\hline Public health worker & 664 & 20.6 \\
\hline Medical technician & 403 & 12.5 \\
\hline \multicolumn{3}{|l|}{ Professional title } \\
\hline No title & 206 & 6.4 \\
\hline Junior level title & 2180 & 67.7 \\
\hline Middle level title & 805 & 25.0 \\
\hline Senior level title & 29 & 0.9 \\
\hline \multicolumn{3}{|l|}{ Years of employment } \\
\hline 1 year and below & 374 & 11.6 \\
\hline $2-5$ years & 776 & 24.1 \\
\hline $6-10$ years & 586 & 18.2 \\
\hline $11-15$ years & 473 & 14.7 \\
\hline $16-20$ years & 438 & 13.6 \\
\hline 20 years and above & 573 & 17.8 \\
\hline \multicolumn{3}{|l|}{ Province } \\
\hline Hubei & 747 & 23.2 \\
\hline Guizhou & 592 & 18.4 \\
\hline Hebei & 441 & 13.7 \\
\hline Guangdong & 850 & 26.4 \\
\hline Zhejiang & 590 & 18.3 \\
\hline
\end{tabular}

\section{Work passion of CHS workers}

Results from the investigation conducted in five Chinese provinces showed that only $63.23 \%$ of the CHS workers expressed that they had work passion for current work but $36.77 \%$ expressed that they didn't have work passion for current work. More than one-third of CHS workers lost their work passion and working enthusiasm.

\section{Assessment of socio-demographic factors influencing the work passion of $\mathrm{CHS}$ workers}

Pearson chi-square test method was used to assess the correlation between all indexes of socio-demographic factors and work passion. The results showed that among the socio-demographic factors of CHS workers, age, professional title, and years of employment were significantly related to CHS workers' work passion $(p<0.05$; Table 2$)$.

\section{Assessment of work-related factors influencing the work passion of $\mathrm{CHS}$ workers}

Pearson chi-square test method was also used to assess the correlation between work-related factors and work passion. The results showed that interpersonal relationships and team atmosphere, learning and training opportunities, compensation packages, opportunity to work autonomously, work stress, and personal development opportunities were significantly related to CHS workers' work passion $(\mathrm{P}<0.05$; Table 3$)$.

\section{Analysis of multiple factors influencing work passion of CHS workers}

To further analyze and determine the factors influencing CHS workers' work passion, we analyzed the significantly related factors $(p<0.05)$ described in the preceding analysis (Pearson chi-square test) by using binary logistic regression method. Dependent variables included the following: having no work passion $(Y=1)$ or having work passion $(Y=0)$ for current job. The results of multiple factors analysis showed that age and years of employment were significantly correlated to CHS workers' work passion loss. The work passion loss probability of CHS workers aged between 25 and 34 was 1.921 times higher than that of CHS workers aged 24 and below $(\mathrm{OR}=1.921,95 \% \mathrm{CI}=1.192-3.095, p=0.007)$. The work passion loss probability of CHS workers with 2 to 5 years and 6 to 10 years of employment was 1.532 times higher $(\mathrm{OR}=1.532,95 \% \mathrm{CI}=1.067-2.165, p=0.011)$ and 2.043 times higher $(\mathrm{OR}=2.043,95 \% \mathrm{CI}=1.215-3.178, p=0.006)$ than that of CHS workers with less than one year of employment, respectively. In addition, the results showed that learning and training opportunities, compensation packages, work stress, and personal development opportunities had positive correlations with the work passion of $\mathrm{CHS}$ workers. The work passion loss probability of $\mathrm{CHS}$ workers who considered learning and training opportunities as the influencing factor of work passion was 1.460 times higher than that of other CHS workers $(\mathrm{OR}=1.460$, $95 \% \mathrm{CI}=1.0532 .024, p=0.023)$. The work passion loss probability of $\mathrm{CHS}$ workers who considered compensation packages as the influencing factor of work passion was 
Table 2 Analysis of socio-demographic factors related to CHS workers' work passion

\begin{tabular}{|c|c|c|c|c|c|c|}
\hline \multirow[t]{2}{*}{ CHS workers } & \multicolumn{2}{|c|}{$\begin{array}{c}\text { Don't have } \\
\text { work passion } \\
(n=1184)\end{array}$} & \multicolumn{2}{|c|}{$\begin{array}{l}\text { Have work } \\
\text { passion } \\
(n=2036)\end{array}$} & \multirow[t]{2}{*}{$x^{2}$} & \multirow[t]{2}{*}{$\mathbf{P}$} \\
\hline & $\mathbf{n}$ & $\%$ & $\mathbf{n}$ & $\%$ & & \\
\hline \multicolumn{7}{|l|}{ Gender } \\
\hline Male & 580 & 49.0 & 994 & 48.8 & & \\
\hline Female & 604 & 51.0 & 1042 & 51.2 & 0.008 & 0.973 \\
\hline \multicolumn{7}{|l|}{ Age } \\
\hline 24 or below & 266 & 22.5 & 462 & 22.7 & & \\
\hline $25-34$ & 397 & 33.5 & 794 & 39.0 & & \\
\hline $35-44$ & 384 & 32.5 & 527 & 25.9 & & \\
\hline $45-54$ & 126 & 10.6 & 212 & 10.4 & & \\
\hline 55 and above & 11 & 0.9 & 41 & 2.0 & 22.906 & $<0.001$ \\
\hline \multicolumn{7}{|l|}{ Educational background } \\
\hline $\begin{array}{l}\text { Secondary technical } \\
\text { school and below }\end{array}$ & 310 & 26.2 & 498 & 24.5 & & \\
\hline Junior college & 675 & 57.0 & 1135 & 55.7 & & \\
\hline Bachelor's degree & 195 & 16.5 & 401 & 19.7 & & \\
\hline Master's degree or above & 4 & 0.3 & 2 & 0.1 & 7.614 & 0.055 \\
\hline \multicolumn{7}{|l|}{ Position } \\
\hline Doctor & 432 & 36.5 & 685 & 33.6 & & \\
\hline Nurse & 384 & 32.4 & 652 & 32.0 & & \\
\hline Public health worker & 241 & 20.4 & 423 & 20.8 & & \\
\hline Medical technician & 127 & 10.7 & 276 & 13.6 & 6.636 & 0.084 \\
\hline \multicolumn{7}{|l|}{ Professional title } \\
\hline No title & 84 & 7.1 & 122 & 6.0 & & \\
\hline Junior title & 759 & 64.1 & 1421 & 69.8 & & \\
\hline Middle title & 329 & 27.8 & 476 & 23.4 & & \\
\hline Senior title & 12 & 1.0 & 17 & 0.8 & 11.085 & 0.011 \\
\hline \multicolumn{7}{|l|}{ Years of employment } \\
\hline 1 year and below & 146 & 12.3 & 228 & 11.2 & & \\
\hline $2-5$ years & 298 & 25.2 & 478 & 23.5 & & \\
\hline $6-10$ years & 192 & 16.2 & 394 & 19.4 & & \\
\hline $11-15$ years & 171 & 14.5 & 302 & 14.8 & & \\
\hline $16-20$ years & 185 & 15.6 & 253 & 12.4 & & \\
\hline 20 years and above & 192 & 16.2 & 381 & 18.7 & 14.092 & 0.015 \\
\hline \multicolumn{7}{|l|}{ Province } \\
\hline Hubei & 283 & 23.9 & 464 & 22.8 & & \\
\hline Guizhou & 213 & 18.0 & 379 & 18.6 & & \\
\hline Hebei & 177 & 15.0 & 264 & 13.0 & & \\
\hline Guangdong & 306 & 25.8 & 544 & 26.7 & & \\
\hline Zhejiang & 205 & 17.3 & 385 & 18.9 & 3.964 & 0.411 \\
\hline
\end{tabular}

1.591 times higher than that of other CHS workers $(\mathrm{OR}=$ $1.591,95 \% \mathrm{CI}=1.084-2.335, p=0.018)$. The work passion loss probability of CHS workers who considered work stress as the influencing factor of work passion was 1.394 times higher than that of other CHS workers $(\mathrm{OR}=1.394$, 95\% CI $=1.004-1.936, p=0.047)$. The work passion loss probability of CHS workers who considered personal development opportunities as the influencing factor of work passion was 1.413 times higher than that of other CHS workers $\quad(\mathrm{OR}=1.413,95 \% \mathrm{CI}=1.037-1.986, \quad p=0.033$; Table 4).

\section{Work satisfaction of CHS workers}

According to the statistical results of the work-related satisfaction degree scores in various aspects, CHS workers were more satisfied with the opportunities to develop capacity for work (average score: $3.67 \pm 0.881$ ), decision-making ability of superior (average score: $3.59 \pm$ 0.855 ), and the stability level of job (average score: $3.55 \pm$ 0.821 ), and were less satisfied with the balance between remuneration and workload (average score: $2.91 \pm$ 1.047), job promotion opportunities (average score: $3.09 \pm 0.865$ ), and working conditions (average score: $3.27 \pm 0.961$; Table 5).

\section{Discussion}

Work passion is a psychological state with the characteristics of strong and positive encouraging emotion, internal driving force, and putting into meaningful work with whole attention,and is having freshness and initiatives in work, having enthusiasm for work and keeping in a good working condition. As the providers of community health services, only CHS workers have work passion for their work can CHS workers team keep sustainability and stability, provide high-quality and efficient medical service for community residents. However, the result of our research showed that $36.77 \%$ of investigated CHS workers expressed that they didn't have work passion for current work. Therefore, we need to further analyze the influencing factors of work passion loss to improve CHS workers' work passion and enthusiasm.

Before discussing the findings of this study, let us study the results of related studies in different countries and regions. In an analysis of socio-demographic factors that influence the work passion, some studies show that age, years of employment, and educational background are correlated with work passion of medical workers $[23,24]$. In terms of the other factors that influence the work passion, studies show that work stress, working environment [25], learning opportunities, personal relationships, personal accomplishment [26], and being trusted and respected [27] are related to work passion of medical workers. Some studies also show that work passion has a significant negative correlation with work dissatisfaction, turnover intention [28], burnout syndrome [29], and emotional exhaustion [30]. Work passion and work satisfaction are two different kinds of psychological 
Table 3 Assessment and analysis of the work-related factors influencing work passion of CHS workers

\begin{tabular}{|c|c|c|c|c|c|c|c|c|}
\hline \multirow[t]{2}{*}{$\begin{array}{l}\text { Assessment on factors may influence work } \\
\text { passion (result in work passion loss) }\end{array}$} & \multicolumn{2}{|c|}{$\begin{array}{l}\text { Don't have work passion } \\
\qquad(n=1184)\end{array}$} & \multicolumn{2}{|c|}{$\begin{array}{l}\text { Have work passion } \\
\qquad(\mathrm{n}=2036)\end{array}$} & \multicolumn{2}{|c|}{ Total } & \multirow[t]{2}{*}{$x^{2}$} & \multirow[t]{2}{*}{ p } \\
\hline & $\mathrm{n}$ & $\%$ & n & $\%$ & n & $\%$ & & \\
\hline \multicolumn{9}{|l|}{ Interpersonal relationships and team atmosphere } \\
\hline Yes & 745 & 62.9 & 1006 & 49.4 & 1751 & 54.4 & & \\
\hline No & 439 & 37.1 & 1030 & 50.6 & 1469 & 45.6 & 55.093 & $<0.001$ \\
\hline \multicolumn{9}{|l|}{ Working conditions and environment } \\
\hline Yes & 635 & 53.6 & 1022 & 50.2 & 1657 & 51.5 & & \\
\hline No & 549 & 46.4 & 1014 & 49.8 & 1563 & 48.5 & 3.537 & 0.060 \\
\hline \multicolumn{9}{|l|}{ Learning and training opportunities } \\
\hline Yes & 728 & 61.5 & 1021 & 50.1 & 1749 & 54.3 & & \\
\hline No & 456 & 38.5 & 1015 & 49.9 & 1471 & 45.7 & 38.792 & $<0.001$ \\
\hline \multicolumn{9}{|l|}{ Compensation packages } \\
\hline Yes & 854 & 72.1 & 1254 & 61.6 & 2108 & 65.5 & & \\
\hline No & 330 & 27.9 & 782 & 38.4 & 1112 & 34.5 & 36.766 & $<0.001$ \\
\hline \multicolumn{9}{|l|}{ Opportunity to work autonomously } \\
\hline Yes & 824 & 69.6 & 1330 & 65.3 & 2154 & 66.9 & & \\
\hline No & 360 & 30.4 & 706 & 34.7 & 1066 & 33.1 & 6.165 & 0.013 \\
\hline \multicolumn{9}{|l|}{ Workload } \\
\hline Yes & 741 & 62.6 & 1203 & 59.1 & 1944 & 60.4 & & \\
\hline No & 443 & 37.4 & 833 & 40.9 & 1276 & 39.6 & 3.829 & 0.05 \\
\hline \multicolumn{9}{|l|}{ Work stress } \\
\hline Yes & 657 & 55.5 & 890 & 43.7 & 1547 & 48.0 & & \\
\hline No & 527 & 44.5 & 1146 & 56.3 & 1673 & 52.0 & 41.596 & $<0.001$ \\
\hline \multicolumn{9}{|l|}{ Personal development opportunities } \\
\hline Yes & 723 & 61.1 & 1002 & 49.2 & 1725 & 53.6 & & \\
\hline No & 461 & 38.9 & 1034 & 50.8 & 1495 & 46.4 & 42.266 & $<0.001$ \\
\hline
\end{tabular}

state, and work passion is significantly and positively influenced by work satisfaction.

The conclusions drawn in this study are similar to those drawn from other countries and regions. According to the results from multivariate analyses, it was showed that among the socio-demographic factors, age and years of employment were significantly related to the work passion of investigated CHS workers. The work passion loss probability of CHS workers between 24 and 34 years old was relatively high, as well as that of CHS workers with 2-10 years of employment. The reason may be that the new generation of young CHS workers was a bit more demanding for their career and selfdevelopment. They are more likely to be disappointed by the reality and loss work passion after working in CHS institutions for a while. According to the results from multivariate analyses, in work-related aspects, learning and training opportunities, compensation packages, work stress, and personal development opportunities all significantly influenced work passion loss of investigated CHS workers.
In order to avoid losing work passion, motivate work passion and enthusiasm of CHS workers, promote their work efficiency, reduce their job burnout and turnover intention, make CHS workers provide high-quality medical services to community residents, the government officials and CHS institutions administrators should pay attention to these influencing factors and focus on the demands of CHS workers. What should be done most by government officials and CHS institutions administrators at present mainly include four aspects. 1) The government officials and CHS institutions administrators should more concern for the working status and psychological state of CHS workers, especially the new generation of young CHS workers, and help them solve problems. 2) The government officials and CHS institutions administrators should improve the system of compensation packages, promote income levels, and balance the relationship between income, technical value and workload of CHS workers. 3) The CHS institutions administrators should properly assign and arrange work, improve working environment and conditions for CHS workers, in order to 
Table 4 Multiple factors analysis of the influencing factors of CHS workers' work passion

\begin{tabular}{|c|c|c|c|c|c|}
\hline CHS workers & Reference to classification & B & $p$ & OR & $95 \% \mathrm{Cl}$ \\
\hline Age & 24 or below & & & & \\
\hline $25-34$ & & 0.653 & 0.007 & 1.921 & $(1.192,3.095)$ \\
\hline $35-44$ & & -0.556 & 0.060 & 0.573 & $(0.321,1.024)$ \\
\hline $45-54$ & & -0.444 & 0.230 & 0.641 & $(0.310,1.325)$ \\
\hline 55 and above & & 0.167 & 0.810 & 1.182 & $(0.304,4.601)$ \\
\hline Professional title & No title & & & & \\
\hline Junior title & & -0.020 & 0.947 & 0.980 & $(0.544 .1 .767)$ \\
\hline Middle title & & -0.604 & 0.070 & 0.546 & $(0.284,1.051)$ \\
\hline Senior title & & -1.264 & 0.108 & 0.283 & $(0.061,1.318)$ \\
\hline Years of employment & 1 year and below & & & & \\
\hline $2-5$ years & & -0.669 & 0.011 & 1.532 & $(1.067,2.165)$ \\
\hline $6-10$ years & & -0.888 & 0.006 & 2.043 & $(1.215,3.178)$ \\
\hline $11-15$ years & & -0.001 & 0.997 & 0.999 & $(0.507,1.965)$ \\
\hline $16-20$ years & & 0.104 & 0.782 & 1.109 & $(0.532,2.314)$ \\
\hline 20 years and above & & 0.652 & 0.092 & 1.920 & $(0.899,4.104)$ \\
\hline Interpersonal relationships and Team atmosphere & no & & & & \\
\hline Yes & & 0.233 & 0.118 & 1.263 & $(0.943,1.691)$ \\
\hline Learning and training opportunities & no & & & & \\
\hline Yes & & 0.379 & 0.023 & 1.460 & $(1.053,2.024)$ \\
\hline Compensation packages & no & & & & \\
\hline Yes & & 0.465 & 0.018 & 1.591 & $(1.084,2.335)$ \\
\hline Opportunity to work autonomously & no & & & & \\
\hline Yes & & -0.073 & 0.717 & 0.930 & $(0.627,1.380)$ \\
\hline Work stress & no & & & & \\
\hline Yes & & 0.332 & 0.047 & 1.394 & $(1.004,1.936)$ \\
\hline Personal development opportunities & no & & & & \\
\hline Yes & & 0.369 & 0.033 & 1.413 & $(1.037,1.986)$ \\
\hline
\end{tabular}

Table 5 Satisfaction degree of CHS workers in all aspects

\begin{tabular}{lccc}
\hline Option & N & Mean & SD \\
\hline Opportunities to develop capacity for work & 3220 & 3.67 & 0.881 \\
Decision-making ability of superior & 3220 & 3.59 & 0.855 \\
The stability level of job & 3220 & 3.55 & 0.821 \\
Superior's attitude toward subordinate & 3220 & 3.51 & 0.936 \\
Self-decision in completing the job & 3220 & 3.43 & 0.939 \\
Methods and measures for implementing & 3220 & 3.38 & 0.853 \\
organization policies & & & \\
Sense of achievement from work & 3220 & 3.34 & 0.906 \\
Working conditions & 3220 & 3.27 & 0.961 \\
Job promotion opportunities & 3220 & 3.09 & 0.865 \\
Balance between remuneration and workload & 3220 & 2.91 & 1.047 \\
\hline
\end{tabular}

reduce their work stress. 4) More learning and training opportunities and more personal development opportunities should be provided and created to CHS workers by the government and CHS institutions administrators, in order to help them to improve their professional level and meet their individual development requirements.

According to the results on work satisfaction in many aspects, investigated CHS workers were most dissatisfied with the balance between remuneration and workload, and job promotion opportunities. These findings indicated that CHS workers thought that their current remuneration does not match their workload and were therefore dissatisfied with their current remuneration. CHS workers were also not satisfied with the current promotion opportunities and thought that the learning and training opportunities and personal development space provided currently to them do not meet their requirements. Work passion is significantly and positively influenced by work satisfaction [31]. Therefore, the results of investigation on 
work satisfaction also reflected the influencing factors of work passion of CHS workers and proved that remuneration and job promotion opportunities would influence work passion, which were similar with the results from multivariate analyses of factors influencing the work passion. Improving work satisfaction of CHS workers can help them avoid losing work passion. Government officials and CHS institutions administrators should pay attention and take measures to improve and promote the work satisfaction of CHS workers, especially balancing remuneration and workload and providing job promotion opportunities for CHS workers.

\section{Conclusions}

The results of this study showed that over one-third of the investigated CHS workers didn't have work passion for current work. The main influencing factors for this finding were work stress, compensation packages, learning and training opportunities, and personal development opportunities of CHS workers, which didn't meet their requirements and dissatisfactory. This finding showed that work passion also related with socio-demographic factors of CHS workers, such as age and years of employment. We suggest government officials and CHS institutions administrators concern for CHS workers' working status and work-related demands, pay attention to and meet their demands for reasonable compensation packages and self-development, balance the income and workload, provide more learning and training opportunities and personal development opportunities for CHS workers, in order to promote CHS workers' work satisfaction, improve their work passion and enthusiasm, reduce the possibilities of job burnout and turnover intention, and make them determined to provide high-quality and efficient medical services to community residents. Government departments and organizations must prioritize these steps and fully understand the significance of arousing and maintaining the work passion of the CHS workers' team for CHS development.

\section{Competing interests}

We declare that we have no competing interests.

\section{Authors' contributions}

$Z L, X B, R M, P F$ participated in literature search and the design of the study. $\mathrm{ZL}, \mathrm{XB}, \mathrm{RM}, \mathrm{CT}$ took part in survey and data analysis. ZL contributed to data interpretation and the writing of the article. All authors have read and approved the final version.

\section{Acknowledgments}

This research was supported by China-Australia Health and AIDS project "Human Resource Development and System Design in Community Health Service Institutions in Urban Areas in China", a three-year project found by the Australian Agency for International Development (Aus AID).

\section{Author details}

'School of Health and Medicine Management, Tongji Medical College, Huazhong University of Science and Technology, 13 Hangkong Road, Wuhan, Qiaokou District 430030, China. ${ }^{2}$ School of Health Management,
Guangzhou Medical University, Guangzhou 510182, China. ${ }^{3}$ School of Management, Hubei University of Chinese Medicine, Wuhan 430065, China.

Received: 17 October 2013 Accepted: 25 April 2014

Published: 1 May 2014

\section{References}

1. Liu SM: Comparison between domestic CHS mode and abroad CHS mode and reference from abroad CHS mode. Chin Prim Health Care 2012, 26:21-23.

2. Murthy NR, Okunade AA: Managed care, deficit financing and aggregate health care expenditure in the United States: a Co-integration analysis. Health Care Manag Sci 2000, 3:283-290.

3. Bhattacharyya O, Delu Y, Wong ST, Bowen C: Evolution of primary care in China 1997-2009. Health Policy 2011, 100:174-180.

4. Jian W, Lina W, Qingyue M: Analysis on benefit of patients flow from general hospitals to community health service facilities. Chin Health Econ 2006, 25:45-47.

5. Dupuit S, Collins E, Shergill S: Computer-based assistance in family medicine. Comput Methods Prog Biomed 1998, 55:201-203.

6. Martinc MR, Menab J, Sketris IS: Collaborative practice in health systems change: the nova scotia experience with the strengthening primary care initiative. Can J Nurs Leadersh 2004, 17:33-45.

7. Shi P, Wu JY, Fu XB, Li P, Song RQ, Gu Y: Investigation on opinions about the establishment of general practitioner system among general practitioners. Chinese Gen Pract 2012, 15:362-366.

8. Liang $H, Y u X$, Chou YB: Analysis on policy issues of community health services in the context of new health care reform. Chin J Health Policy 2010, 3:2-8.

9. Liang WN, Li J, Guan J, Yang XH: The investigation of the present situation of national community health service: the present situation of health workforce of national community health service centers and comparison in different areas. Chinese General Practice 2005, 8:1038-1041.

10. Ministry of Health of the People's Republic of China: The National Health Service in April. In Beijing: Information Statistics Center of Ministry of Health of the People's Republic of China; 2013.

11. Huang Y, Wamg Q, Li CQ: The development, current situation and problems of the community health services in China. Prog Mod Biomed 2010, 10:2795-2800.

12. Zhu LN, Dai S, Lou Y, Guo Q: A satisfaction and demand survey on community health service after health care reform in Hangzhou. Health Res 2012, 32:51-54.

13. Yang HF, He H: Investigation of the utilization of community health services and satisfaction degree of community residents in Urumqi city. Mod Prev Med 2013, 40:259-261.

14. Luo WZ: Study development on improving Chinese urban CHS countermeasures. Today Nurs 2013, 2:9-10.

15. Chen C: Simple analysis on urban CHS work. J Community Med 2012 10:23-24.

16. Shi CC: Factors influencing degree of satisfaction of community residents with CHS. Chin Community Workers 2012, 14:395-396.

17. Fan CP, Sun SX, Gong X, Li: Staff's satisfaction and their stability in community health service institutions of 3 piloting cities in China. Chin Gen Pract 2010, 13:3497-3499.

18. Zhang LL, Li X, Ding HY: Investigation and analysis of health human resources in the community health service under the framework of medical reformation. Chin J Gen Pract 2013, 11:452-453.

19. Kun L: Talent team building is key for CHS development. Chin Community Workers 2006, 22:3.

20. Zhang EY, Chen J: Analysis on satisfaction degree of CHS medical workers in district in Beijing. Chin J Health Policy 2011, 4:44-47.

21. Vallerand RJ, Yvan P, Frederick LP, Julie C: On the role of passion for work in burnout: a process model. J Pers 2010, 78:289-312.

22. Donahue EG, Forest J, Vallerand RJ, Lemyre PN, Crevier-Braud L, Bergeron E: Passion for work and emotional exhaustion: the mediating role of rumination and recovery. Appl Psychol Health Well-being 2012, 4:341-368.

23. Qin HJ: Thoughts on the development and reform of community health service in China. Chin J Health Policy 2012, 5:1-3.

24. Thasler WE, Kleespies A, Thasler R, Jauch KW: Passion and Commensurability: both are needed for a concurrence of surgery and research. Langenbeck's Arch Surg 2013, 398:485-486. 
25. Sun K, Yin WQ, Wang ZD, Li YL: Review on work lassitude of workers. Chin Health Qual Manag 2009, 16:123-126.

26. Wang X, Kunaviktikul W, Wichaikhum OA: Work empowerment and burnout among registered nurses in two tertiary general hospitals. J Clin Nurs 2013,

27. Zhang ZT: How to motivate the work passion of staff. Sci Technol Innovation Herald 2010, 8:206

28. Blankertz LE, Robinson SE: Turnover intentions of community mental health workers in psychosocial rehabilitation services. Community Ment Health J 1997, 33:517-529.

29. Swetz KM, Harrington SE, Matsuyama RK, Shanafelt TD, Lyckholm L: Strategies for avoiding burnout in hospice and palliative medicine: peer advice for physicians on achieving longevity and fulfillment. J Palliat Med 2007, 12:773-777.

30. Green AE, Miller EA, Aarons GA: Transformational leadership moderates the relationship between emotional exhaustion and turnover intention among community mental health providers. Community Ment Health J 2013, 49:373-379.

31. Ching-I T, Yea-Ing LS, Hao-Yuan C: Moderating effects of professional commitment on hospital nurses in taiwan original research article. J Prof Nurs 2007, 23:47-54.

doi:10.1186/1471-2296-15-77

Cite this article as: Luo et al:: Factors influencing the work passion of Chinese community health service workers: an investigation in five provinces. BMC Family Practice 2014 15:77.

\section{Submit your next manuscript to BioMed Central and take full advantage of:}

- Convenient online submission

- Thorough peer review

- No space constraints or color figure charges

- Immediate publication on acceptance

- Inclusion in PubMed, CAS, Scopus and Google Scholar

- Research which is freely available for redistribution 